\title{
Avaliação de um Investimento em Pesquisa Adicional num Novo Processo de Produção: Considerações Metodológicas e uma Aplicação
}

\section{Cesar das Neves}

Prof. Adjunto do Depto. Engenharia Industrial/EEUFRJ)

Consultor na área de elaboração e análise de projetos de investimentos (públicos e privados)

Palavras-chave: risco, teoria da decisão, análise de investimentos, avaliação de projetos de pesquisa, análise de risco, engenharia econômica

Key words: decision theory, analysis of investment, risk analysis

\section{RESUMO:}

O artigo discute a análise de projetos de investimento nos quais não se adequa a hipótese de risco crescente no tempo. Este é o caso de investimentos em pesquisa, onde a cada etapa vencida, diminuem-se os riscos de insucesso do projeto. Mostra-se que projetos deste tipo, se avaliados segundo o critério usual de método de fluxo de caixa descontado a uma taxa que incorpora um prêmio de risco, são sistematicamente rejeitados. A presenta-se um estudo de caso, baseado numa experiência real conduzida no âmbito de uma empresa privada, onde foi aplicada a teoria de árvore de decisāo.

\begin{abstract}
:
This paper discusses the analysis of investment in projects where the hypothesis of increasing risk is not aslequate. This is particularly the case of investment in research projects where each completed stage decreases the risk of following stage failure. Projects of this kind are almost always rejected where evaluated by the discount cash flow methods which use discount rates including risk premium. It is presented here a case study based on an actual cxperience conducted inside a private firm solved by the application of decision trec theory.
\end{abstract}

Rec. 05/91 Rev. 05/91 Apr. 06/91 


\section{Introdução}

Este trabalho, partindo de um sistuação real analisada para uma empresa, procura mostrar como a técnica usual de análise de investimentos deve ser aplicada com cuidado, em se tratando de projetos que tenham fases de risco diferenciadas. Este é o caso de projetos que envolvam decisões de investimentos em pesquisa. Pode-se dizer que as considerações realizadas neste trabalho se aplicam a quaisquer projetos de pesquisa ou de desenvolvimento. Mas, para facilidade de exposição vamos nos ater a um projeto específico que contempla a utilização de um processo metalúrgico conhecido a nível teórico, mas ainda não testado na produção de um ferro liga.

A análise de investimentos em projetos que envolvem gastos em pesquisa (1), tem sido objeto de diversas propostas metodológicas. Nosso objetivo neste trabalho não é o de discutir estas metodologias, mas tão somente mostrar como a tradicional técnica de análise do fluxo de caixa descontado tem sido mal utilizada pelos analistas de projetos e de como torná-la um efetivo instrumento para tomada de decisāo numa empresa.

O trabalho será desenvolvido sob a ótica da empresa privada. Isto não significa que os conceitos aqui desenvolvidos se restringem a esta esfera de análise. Com pequenas adaptaçōes (basicamente a de passar dos preços de mercados para os preços "sombra") pode-se, com facilidade, usar a mesma metodologia para análises mais globais dos projetos enfocando sua contribuição para o bem estar social.
Pretende-se mostrar que a aplicação inadequada do método tradicional de análise do fluxo de caixa descontado tem levado muitas empresas a rejeitarem investimentos com as características abaixo descritas, refletindo no longo prazo, em uma tremenda perda de oportunidades de crescimento e desenvolvimentode novas linhas de negócio.

Consideramos desnecessáriocaracterizar o desenvolvimento e crescimento empresarial dos países queoptaram poraltos investimentos em pesquisa tecnológica como o Japão. Como foi observado por Hayes e Abernathy (1980), os Estados Unidos quase que perderam a trilha do desenvolvimento econômico ao enfatizarem a rentabilidade decurto prazo vis a vis a postura japonesa de rentabilidade de longo prazo. Deixaremos este assunto fora da presente discussão.

O projeto a que se refere o caso prático será simplificadoe descaracterizado quanto a seus valores financeiros e resultados esperados. Quer-se, com isto, preservar a confidencialidade dos dados e da empresa. Deste mesmo modo a descrição do contexto da análise não corresponde exatamente ao caso real.

\section{Contexto da análise}

Trata-se de um projeto que contempla a produção de um certo tipo de ferro liga. A tecnologia convencional tem comocaracterística um alto consumo de energia. A região onde se situa o minério é carente deste fator

(1) Optamos notexto por uma distinção entre projetos de pesquisae que envolvam gastos em pesquisa. Enquantoque o primeiro se refere a projetos cujo produtoé o resultado da pesquisa (que pode ser utilizado com várias finalidades), no segundo esta aparece como uma etapa do projeto, sendo o produto final um bém normalmente comercializado no mercado. Nossas consideraçöes se aplicam a ambos os casos, porém, para o promeiro, seria necessário extender a análise. 
de produção, podendo ser obtida somente a altos custos, o que inviabiliza o projeto segundo esta concepção tradicional.

A empresa se envolveu num projeto de pesquisa para obtençãodo produto poroutro processo, cuja característica é o baixo consumodeenergia elétrica com significativa redução do custo operacional, mesmo com geração própria de energia, e ainda descréscimos de investimento em capital fixo em relação ao projeto convencional. Este novo processo ainda não foi utilizado para a produção industrial deste ferro liga em particular, envolvendo riscos de diversas naturezas (tecnológicas).

Os resultados obtidos pela pesquisa indicaram que é possível utilizar este processo na produção do ferro liga, sendo cogitado pela empresa um projeto envolvendo gastos de US\$10 MM, com uma geração líquida anual de caixa de US\$ 1.6 $\mathrm{MM}$, após consideração dos impostos, num horizonte de planejamento de 20 anos.

Sob a ótica da empresa gestora o projeto é de pequeno porte, mas as incertezas associadas à nova tecnologia levam-na a adotar uma postura conservadora, limitando a escala do empreendimento.

A empresa considera atraente um retorno de $9,5 \%$ a.a. se de pequeno (livre) risco e, devido às incertezas associadas ao projeto, adicionaria um prêmiode risco (multiplicativo) de $5 \%$, sendo entãoem torno de $15 \%$ a.a. a taxa mínima desejada para o empreendimento.

Quer-se analisar a conveniência da implantação imediata do projeto ou se deve prosseguir com os investimentosem pesquisa, cuja próxima etapa seria a de construção de um forno piloto para experimentaçōes e ajuste do processo envolvendo mais US\$ 2 $\mathrm{MM}$, delongando a implantação do projeto pormais 1 ano. Dados complementares serão fornecidos adiante.

\section{A análise de projetos envolvendo gastos em pesquisa}

Sob aótica da empresa privada um projeto que envolva gastos em pesquisa para desenvolvimento de um produto é normalmente analisado pelo fluxo de caixa descontado. A regra utilizada tem sido a de comparar a taxa de retorno do projeto com uma taxa mínima de retorno que considera uma rentabilidade livre de risco mais um prêmio de risco do empreendimento. Em termos do métododo valor atual istoequivale a calcular o valor presente líquido dado por:

$$
\begin{aligned}
& \operatorname{VA}\left(i_{e}\right)=-\sum_{t=0}^{t_{0}} \frac{I(t)}{\left(1+i_{e}\right)^{t}}+ \\
& +\sum_{t=t_{1}}^{T} \frac{R(t)-C(t)}{\left(1+i_{e}\right)^{t}}
\end{aligned}
$$

onde:

$i_{e}$ - taxa mínima de retorno do empreendimento;

$I(t)$ - investimentos do projeto (capital fixo, pesquisa, capital de giro etc., no ano $t$; $R(t)$ - receitas oriundas do projeto no ano $t$; $C(t)$ - custos (operacionais, administrativos, financeiros etc.) do projeto no ano t;

$\left(\mathrm{O}, \mathrm{t}_{\mathrm{n}}\right)$ - período de implantação;

$\left(t_{1}, T\right)$ - período de operação.

e comparar com o valor nulo, sendo projetos com valor atual positivo (negativo) aprovado (reprovado). 
Consideramosem (1) os valoresexpressos em moeda constante tal que a taxa mínima de retorno seja formada por apenas dois componentes:

$$
\left(1+\mathrm{i}_{\mathrm{e}}\right)=\left(1+\mathrm{i}_{\mathrm{lr}}\right) \cdot\left(1+\mathrm{i}_{\mathrm{re}}\right)
$$

ou simplesmente:

$$
i_{e}=i_{t r}+i_{r e}+i_{t r} \cdot i_{r e}
$$

onde:

$i_{1 e}$ - taxa de retorno livre de risco

$i_{r e}$ - prêmio de risco devido à natureza do empreendimento

A aplicação do método do fluxo de caixa descontado acima, sem maiores cuidados, poderia induzir o seguinte raciocínio: tratase de um projeto cuja implementação imediata levaria a empresa a tercomoexpectativa uma taxa de retorno de cerca de $15 \%$ a.a. Esta taxa está em torno da mínima desejada pela empresa para este tipo de empreendimento.Desta maneira o projeto nãose revela, nem atraente a ponto de entusiasmar os executivos da empresa, nem desestimulante o suficiente, para ser descartado. $O$ investimento em pesquisa adicional delongaria a implantação do projetoe ainda exigiria mais capital gerando uma taxa de retorno de $10,6 \%$ a.a o que viria a inviabilizá-lo definitivamente.

A utilização deste tipo de procedimento tem levadoasempresas a rejeitarem sistematicamente projetos de investimento que envolvam investimentos em pesquisa ou a aprovarem alternativas que limitam a competitividade da empresa em termos de custos, devido a questōes de escala.

De fato, os projetos desta natureza têm fluxos de caixa bastante incertos, oque induz as empresas a considerarem apenas alternativasextremamente conservadoras (pequena escala, mercado restrito, etc.) aliadas à exigência de taxas mínimas de retorno, elevadas ao incorporarem alto prêmio de risco. Como consequência da primeira postura, a alternativa selecionada, se alguma, perde sua competitividade e, como consequência da segunda, alternativas de longa maturação são prontamente rejeitadas. Em decorrência, projetos que envolvam investimentos em pesquisa são sistematicàmente rejeitados. Primeiramente, porque este tipo de projeto tem, em geral, longa maturação, não suportandoexigências de taxas elevadas e em segundo lugar porque alternativas conservadoras formu ladasà luz das incertezas dificilmente remunerarãoocapital investido. A desconsideração deste fato pelas empresas tem geradouma postura extremamente pessimista quanto a gastos em pesquisa em geral.

Note-se que nãoqueremos jogar sobre as empresas o ônus de assumir investimentos inviáveis pelo mérito destes incluírem gastos em pesquisa. Trata-se, antes de tudo, de uma falsa interpretação do conceito de fluxo de caixa descontado e da utilização do prêmio de risco incorretamente, com a empresa desprezando oportunidades atraentes de investimentos.

O uso de uma taxa mínima de retorno mais elevada, dada pela equação(2), implica em uma hipótese de incerteza crescente com o tempo da forma exponencial, isto é:

$$
\alpha_{1}=\frac{1}{\left(1+i_{r e}\right)^{t}}=e^{-i_{r}^{*}+}
$$

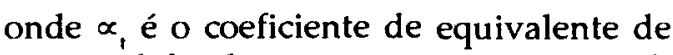
certeza, definido comooquanto (percentualmente) a empresa está disposta a trocar de seu fluxo de caixa incerto no ano $t$, pelo fluxo certo, sendo $\mathrm{i}_{\mathrm{re}}^{*}$ a taxa de juros contínua equivalente a $\mathrm{i}_{\mathrm{r}}^{\circ}$ [ver Van Horne (1979)]. 
A figura 1 nos mostra ovalor dos coeficientes de certeza para taxas de juros de $3 \%$ e $5 \%$. Uma taxa adicional como prêmio de risco de 5\% implica que a empresa está disposta a trocar 1 u.m. (uma unidade monetária) incerta prevista para o décimo ano por 0,61 u.m. garantida, também para o décimo ano.

Uma vez compreendida esta implicação, fica claro que a adição de um prêmio de risco para determinação da taxa mínimá de retornoem projetosqueenvolvam investimentos em pesquisa é inapropriada. Note-se que a pesquisa, uma vez bem sucedida, vem a diminuir as incertezas referentes ao projeto e incerteza descrescente no tem po é contraditória com a adição do prêmio de risco.

Nãose trata ainda de utilizarsimplesmentetaxasdiferenciadas para as diversas etapas do projeto. Isto, conforme bem advogado por Hodder e Riggs (1985), pode e deve ser feito, mas a não consideração explícita das diversas etapas pode obscurecer o processo

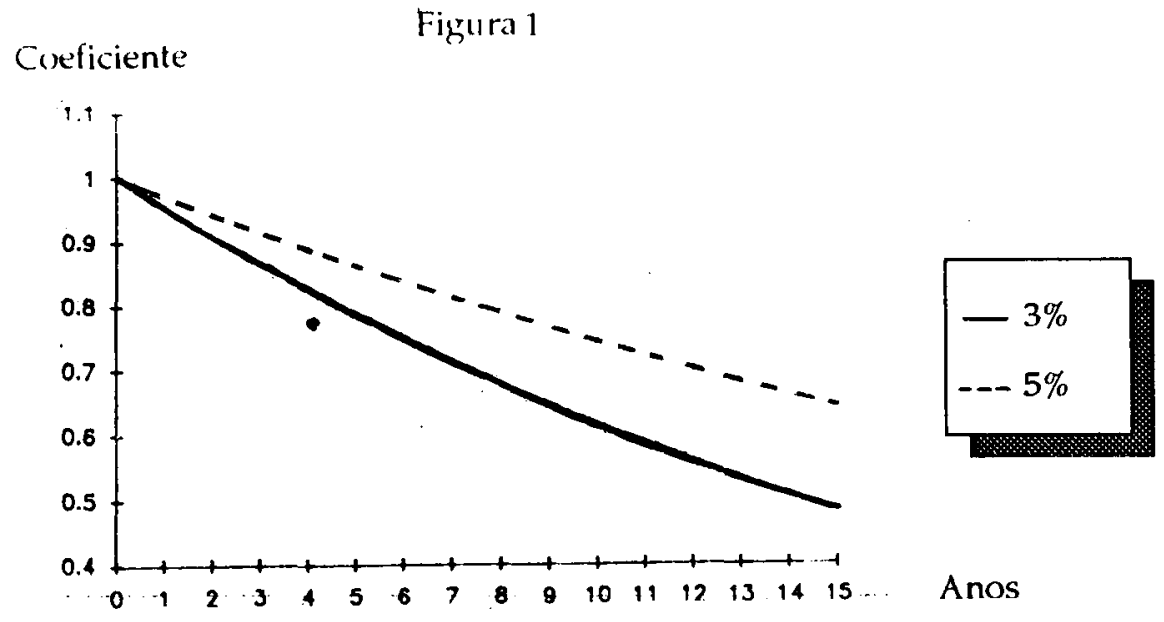

decisório. Ao término de cada etapa do projeto a empresa poderá ter caminhos alternativos a seguir. Caminhos que ficam embolados senãosãotratados separadamente. Por exemplo, no caso em questão, após o término da etapa de pesquisa eem funçãode seus resultados a empresa poderá decidirse prossegue ou não com o projeto. A decisão econômica tem que ser avaliada por etapas. $\mathrm{Na}$ primeira etapa seriam analisadas as questōes do tipo: "vale a pena investir no projetode pesquisa?"; "atéque valor?";" para que taxa mínima de retorno?". Na segunda etapa as perguntas considerariam os resultados da pesquisa e seriam do tipo: "vale a pena prosseguir com o projeto?"; " para que taxa mínima de retorno"; "quais os riscos da pesquisa ter dado indicaçōes incorretas?".
A análise destas questões fica bastante simplificada com o auxílio da técnica da árvore de decisão.

\section{Uso das árvores de decisão na análise de investimentos}

A técnica das árvores de decisão foi incorporada na análise de investimento já na década de 60 (ver Magee (1964)). Não nos deteremos na exposiçăo desta metodologia, mas simplesmente em mostrar como a utilização desta técnica pode resolver satisfatoriamente o problema em questão (ver Neves (1981)). 
A técnica foi inialmente desenvolvida para oestudo de decisōes sequenciais, sendo depois estendida para a análise do valor de uma informação, seja ela perfeita (clarividência) ou imperfeita (ver Costa Neto (1980)).

Pode-se perfeitamente considerar que pesquisas produzem conhecimento e como tal podem ser analisadas pela teoria da decisão, segundo o mesmo procedimento de avaliação de uma informação imperfeita. A outra maneira de obter informação é por consultas a especialistas.

Uma outra observação, que pode passar desapercebida pela empresa, é que um resultado favorável da pesquisa pode levar a concepções mais arrojadas do projeto.
No caso em questão, o risco envolvido pôde ser considerado somente de natureza tecnológica, havendo mercado, capacidade gerencial, crédito etc., para projetos de maior escala que a da concepção inicial.

Assim sendo, considerou-se que, caso a pesquisa indicasse resultados favoráveis poder-se-ia simplesmente dobrara capacidade do projeto aproveitando-se de uma economia de escala de 0,77 em relação aos investimentos. Suporemos uma estrutura de custos variáveis, dobrando-se a caixa gerada ao se duplicar a capacidade.

O projeto com suas concepçóes alternativas podeentão ser representado pela árvore da figura 2.

Figura 2

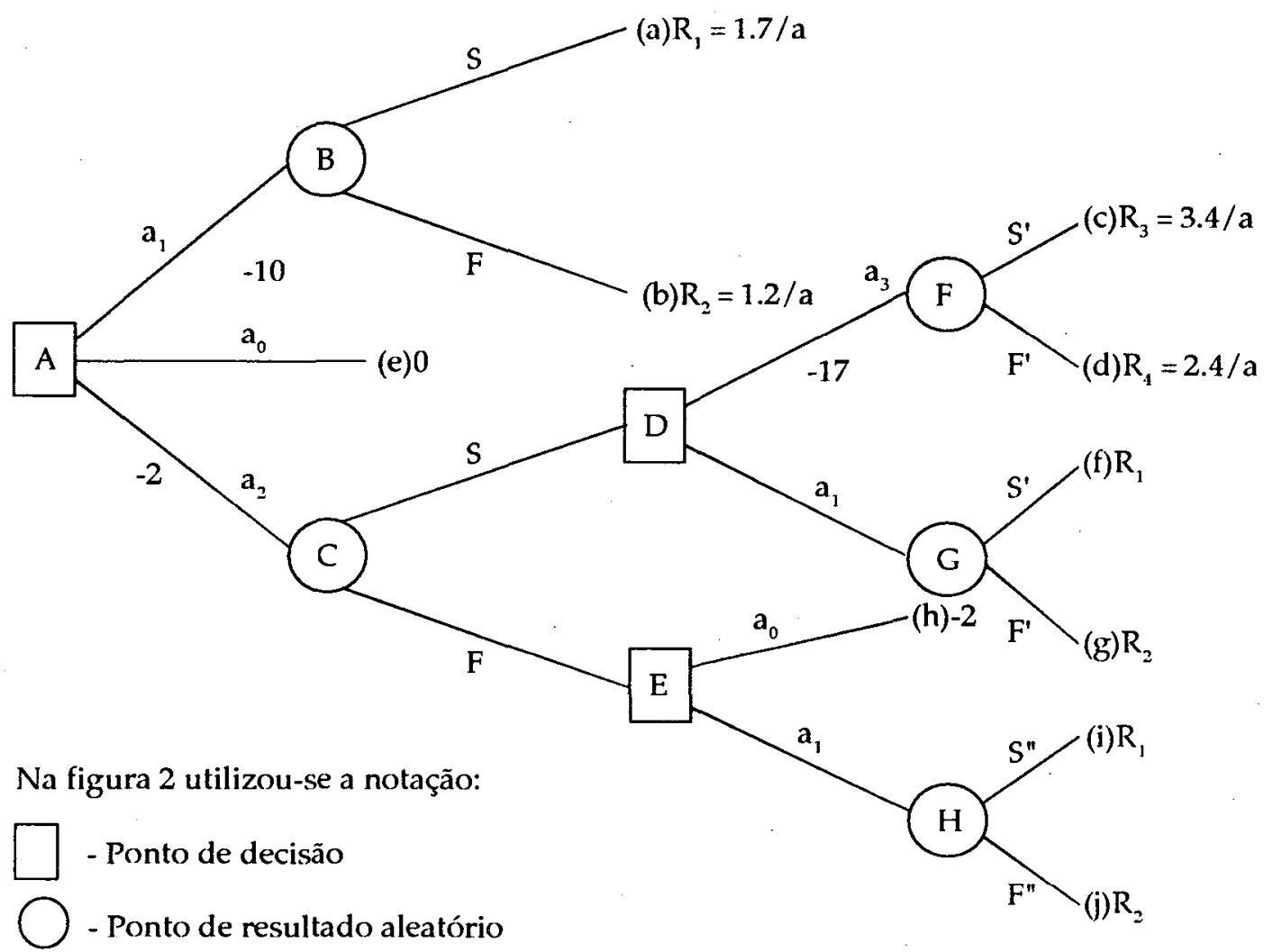


A resolução da árvore, isto é, qual a sequência de decisóes recomendadas, requer o conhecimento, que pode ser bastante aproximado, das probabilidades doseventos aleatórios, bem como dos resultados esperados ao fim de cada ramo.

Para esta análise é necessárioque se estime probabilidade de erro e acertos da pesquisa, mais especificamente:

- a probabilidade de se ter sucesso quando a pesquisa indica sucesso;

- a probabilidade de se ter sucesso quando a pesquisa indica fracasso;

- a probabilidade de se ter fracasso quando a pesquisa indica sucesso;

- a probabilidade de se ter fracasso quando a pesquisa indica fracasso;

Para simplificar reduzimos os resultados do projeto a "sucesso" e "fracasso", mas nada impede a consideração de vários possíveis resultados. Note-se ainda que estas probabilidades são condicionadas e sua determinação fica simplificada com a ajuda do teorema de Bayes de probabilidade condicionais:

$$
P\left(E_{i} / A\right)=\frac{P\left(E_{i}\right) \cdot P\left(A / E_{i}\right)}{\forall i \sum^{P\left(E_{i}\right) \cdot P\left(A / E_{i}\right)}}
$$

sendo:

$P\left(E_{i} / A\right)$ - probabilidade do evento dadoque A ocorreu;

$P\left(E_{i}\right)$ - probabilidade (incondicional) do evento $E$;

$C$-espaço amostral (conjunto de possibilidades) do experimento.
A aplicação da fórmula de Bayes necessita do conhecimento das probabilidades incondicionais (a priori) do projeto vira a ser bem (sucesso) ou mal sucedido (fracasso) devido ao risco tecnológico. Consideramos no exemplo as probabilidades da tabela 1 abaixo.

Tabela 1 - Distribuiçāo Prévia

\begin{tabular}{|cc|}
\hline Do projeto ter: & Probabilidade \\
Sucesso & 0,80 \\
Fracasso & 0,20 \\
após implantado (independentemente da \\
pesquisa)
\end{tabular}

É necessário caracterizar ainda as características da pesquisa em termos de resultados esperados, mais especificamente:

- a probabilidade da pesquisa indicar sucesso quando de fato o projeto será bem sucedido;

- a probabilidade da pesquisa indicar sucesso quandode fatoo projeto será mal sucedido; - a probabilidade da pesquisa indicar fracasso quando de fato o projeto será bem sucedido;

- a probabilidade da pesquisa indicar fracasso quandode fatoo projeto será mal sucedido;

Estas probabilidades se referem aoagente responsável pela pesquisa naquele tipo de projeto caracterizando sua precisão ou ordem de grandeza de erros (chamados em estatística de erros tipos I e II)

No caso específico, o agente responsável pela pesquisa era uma conceituada em presa de consultoria. Deixaremos porém este aspectosem maiokes considerações e trabalharemoscom asseguintes probabilidades pari o caso em questão 
Tabela 2 - Características do Experimento

\begin{tabular}{|lcccc|}
\hline Probabilidade da consultoria indicar: & Sucesso & Fracasso & \\
& & "S" & "F & Total \\
Quando o projeto terá: & & & \\
Sucesso & S & 0,95 & 0,05 & 1 \\
Fracasso & $\mathrm{F}$ & 0,03 & 0,97 & 1 \\
\hline
\end{tabular}

A aplicação do teorema de Bayes nos dará as probabilidades condicionais: $\mathrm{P}(\mathrm{S} /$ "S"), $P\left(F^{\prime \prime} S^{\prime \prime}\right), P(S / " F ")$ e $P\left(F /{ }^{n} F "\right)$, denotadas na figura 3 , por $p_{s}{ }^{\prime}, p_{i}{ }^{\prime}, p_{s}{ }^{\prime \prime} e p_{f}{ }^{n}$, respectivamente.

A resolução da árvore se dá de trás para frente: (i) primeiramente, se apurando o resultadolíquido(Valor Presente)aotérmino de cada ramo independentemente das probabilidades; (ii) especificando-se um critério de decisão (valor esperado, valor mais provável etc.); (iii) aplicando-se o critério em cada nó probabilístico; (iv) escolhendo-se a melhor opção em cada nó de decisão. Na figura 3 utilizou-se o critério do valor esperado, assinalado em retângulo acima de cada nó.

Figura 3

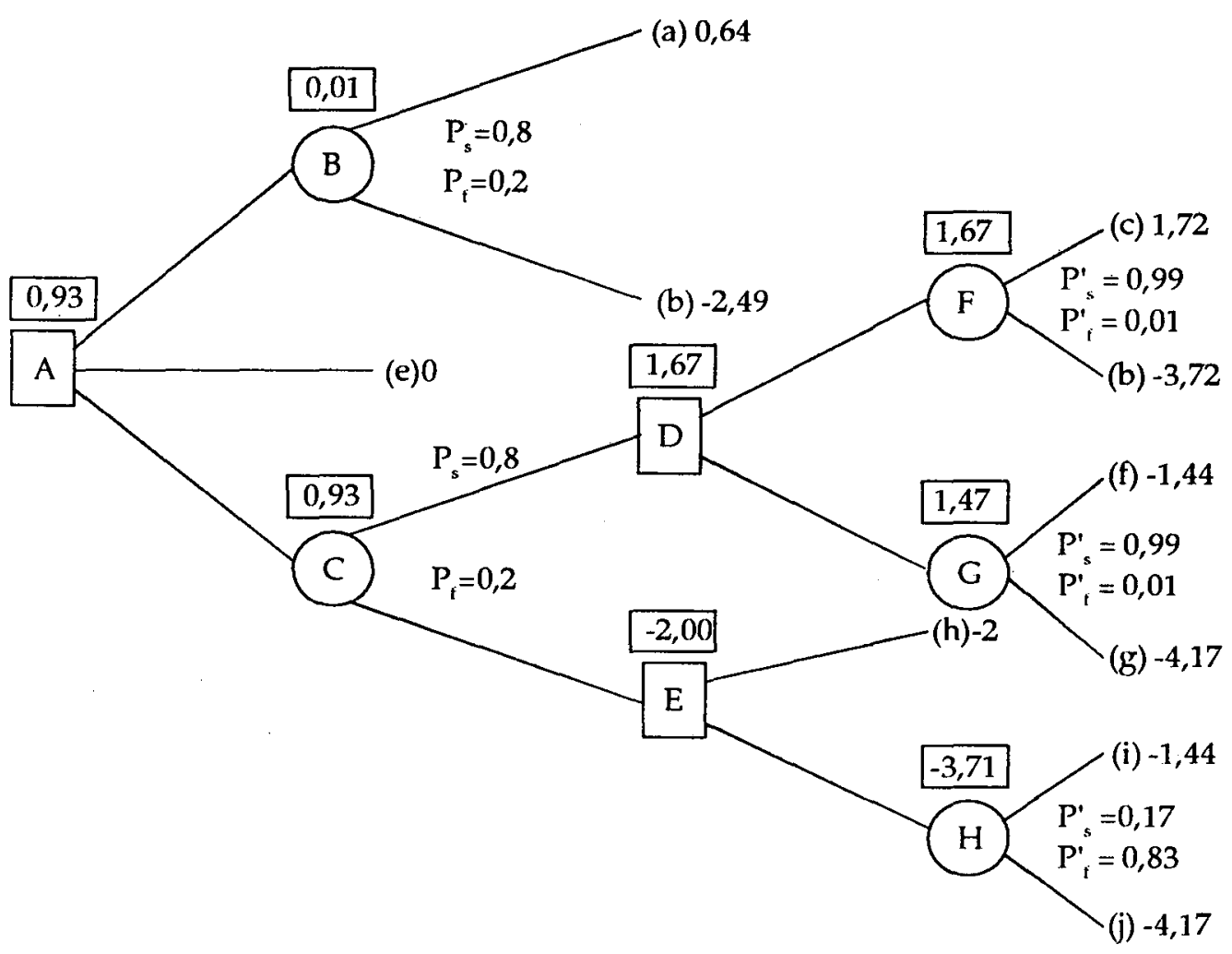


A análise desta figura nos mostra que vale a pena investir em pesquisa adicional melhor caracterizandoos riscostecnológicos do projeto. Caso a pesquisa dê resultados favoráveis, a empresa partiria para concepções mais arrojadas do projeto original. Caso contrário, o projeto deverá ser abandonado. Desta forma, a empresa estará maximizando seus resultados esperados.

\section{Consideração do risco diferenciado}

A aplicação da teoria da decisão permitiu concluir que o investimento em pesquisa adicional para um melhor conhecimentodos riscostecnológicos do projetoé viável devido à possibilidade de uma concepção mais

Figura 3

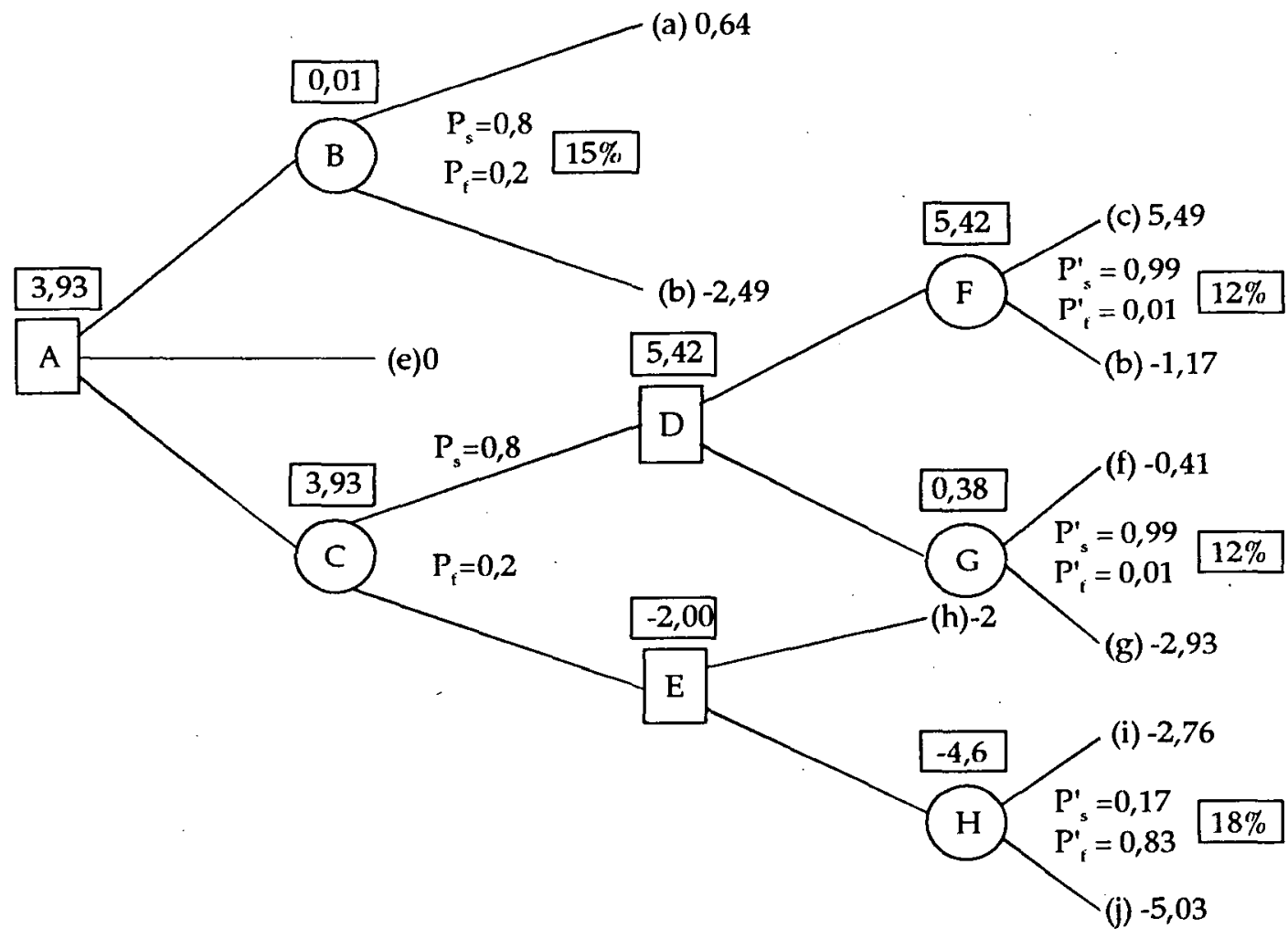

arrojada do projeto frente aos resultados favoráveis da pesquisa. Deve ser observado que, na resolução da árvore (figura 3), utilizou-se uma mesma taxa de retorno em todosos ramos. Conforme mencionadoante- riormente, esta consideração pode ser inapropriada para certos tipos de análises, tais como a análise em questão, dado que o próprio resultadoda pesquisa virá modificar o risco (tecnológico) do projeto.

(2) Estamos evitando considerar outros tipos de risco, tais como os mercadológicos, financeiros etc, para nāo obscurecer a presente análise.

Os pontos aquí levantados podem ser facilmente extendidos a casos mais complexos. 
Desta maneira, deve-se averiguar a taxa de desconto apropriada em cada ramo. Os riscos associados aos ramos (c), (d), (f) e (g) devem ser menores do que em (a) e (b). Do mesmo modo os riscos associados a (i) e (j) são maiores do que os de (a)e(b). Utilizando, $12 \%, 15 \%$ e $18 \%$ para os ramos (c), (d), (f), (g), (a), (b) e (i), (j), respectivamente e resolvendo novamente a árvore temos agora os resultados da figura 4.

$O$ investimento em pesquisa tornou-se muito mais atrativo do que anteriormente detectado. Vê-se que esta é viável ainda que o projeto não permitisse uma concepção mais arrojada (inexistência dos iamos (c) e (d). Vale observar que o resultado da figura 4 difere completamente dosobtidosanteriormente, particularmente do derivado pela aplicação do método do fluxo de caixa descontadoas al ternativas diretamente sem consideração explícita das etapas e taxas de risco apropriadas.

\section{A questão da dificuldades de obtenção dos dados}

Uma questão final precisa ser discutida. Trata-se da dificuldade de obtenção dos dados para aplicaçāo da técnica acima. Neste particular deve ser observadoque, em geral, a solução obtida pela aplicação da teoria da decisãoé robusta para variaçōes nos parâmetros da análise, particularmente quanto às probabilidades. As demais informações são rotineiras a quaisquer estudos de projeto. Deste modo basta atribuir valores razoavel- mente coerentes às probabilidades para se ter uma boa solução do problema.

Para o projetoem discussāo as probabilidades da tabela 2 são as de maiores dificuldades de atribuição de valor. Estas são pertinentes aoexperimentoe poderiam serobtidas de diversas formas: (i) por entrevistas com a consultoria (quais as chances de erros que esta atribui para seus resultados); (ii) com base em experiência passada (como têm sido as previsões de resultados desta empresa em relaçãoà realidade)ou;(iii) mais subjetivamente poder-se-ia pensar nestas probabilidades como "graus de confiança" atribuíveis à empresa para este tipo de experimento.

É conveniente, em caso de grande desconhecimento dos parâmetros da análise, se proceder a uma análise de sensibilidade do problema. Pode-se averiguar uma série de questões do tipo: "até que nível de investimento se justifica a pesquisa?"; "para que variações das probabilidades a priori 0 investimento em pesquisa se justifica?", "para que nivel de prêmio de risco a opção mais arrojada se torna inferior à opçāo inicial mesmo apósos resultados da pesquisa serem satisfatórios?"; "que valores máximos de erro são aceitáveis para a pesquisa se manter viável?"; etc.

Não nosé possivel analisar todas as questões acima mencionadas aqui neste trabalho. Dá-se abaixo, na figura 5, o valor máximo que se podegastar na pesquisa para variaçōes na taxa de desconto nos ramos (c) e (d), correspondente à concepção mais arrojada do projeto.

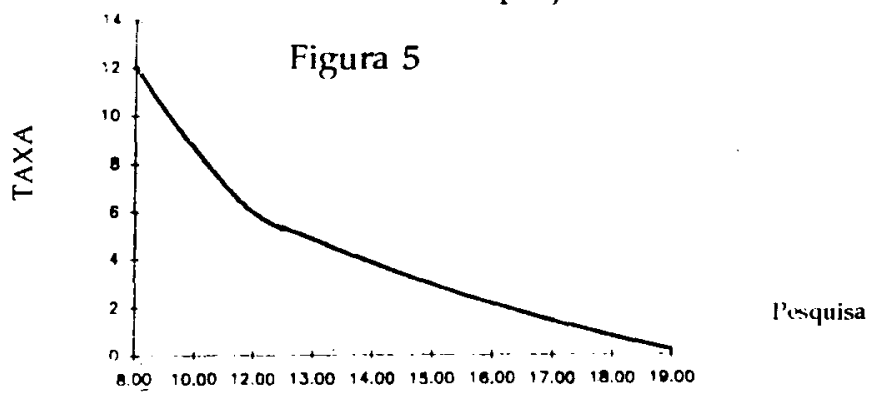




\section{Conclusões}

Discutiu-se neste trabalho a utilização do método do fluxo de caixa descontado com prêmio de risco adicionado à taxa de desconto para a análise de gastos em pesquisa. Tais projetos, de resultados incertos, não se prestam a este tipo de análise, devido a sua natureza de risco, que não se coaduna com a hipótese básica decorrente deste procedimento. Sua aplicação tem levadoas empresas à rejeiçãosistemática de projetos de pesquisa, ou ainda a a provarem concepções medíocres destes projetos perdendo im portantes oportunidades de crescimento em novas linhas de negócio.

Apesar desta constatação não se deve atribuir à técnica em si estas limitaçōes. $\mathrm{Na}$ realidade trata-se mais de sua utilização incorretamente do que propriamente de falhas metodológicas. A sua utilização conjugada com técnicas de teoria da decisão e taxas diferenciadas de risco a cada ramoda árvore mostrou que esta é capaz de avaliar com mais propriedade os projetos envolvendo gastos em pesquisa. Além da maior adequabilidade deste tipo de análise o método se mostra capaz de responder a uma série de questões dando maior profundidadeàsanálises realizadas. Não se deve concluir que o método aqui exposto se presta a quailquer tipo de análise. Pelo contrário, quer-se aqui chamar a atenção, exatamente, de comoapli- cações automáticas de técnicas sem considerar se suas hipóteses básicas se adequam ou não ao problema a ser tratado, podem levar as empresas a tomarem decisões falhas.

\section{Bibliografia}

COSTA NETO - A nálise Estatística da Decisāo, Editora Edgard Blücher Ltda, 1980

HAYES, ROBERT H AND WILLIAM J. ABERNATHY - Managing our Way to Economic

Decline, Harvard Business Review, JulyAugust 1980

HODDER, JAMES E. AND HENRY E. RIGGS - Pitfalls in Evaluating Risky Projects, Harvard Business Reviw Jan-Febr, 1985

MAGEE, JOHN F. - Decision Trees for Decision Making, Harvard Business Review, July-August 1964

NEVES, CESAR DAS - Análise de Investimentos: Projetos Industriaise Engenharia Econômica, Zahar Ed. 1981

VAN, HORNE, J.C. - Política e Administração Financeira, Coleção Univesitária de Administração, Ed.Universidade de São Paulo, 1974. 